\title{
INVESTIGATING THE DYNAMICS OF WANDOO CROWN DECLINE WITH TIME SERIES LANDSAT IMAGERY
}

\author{
K. Zdunic ${ }^{\text {a, } *, \text { G. Behn }}{ }^{\text {a }}$, R. van Dongen ${ }^{\text {a }}$ \\ ${ }^{a}$ DEC, GIS Branch, 17 Dick Perry Avenue Kensington, Australia - (Katherine.Zdunic, Graeme.Behn, \\ Ricky.vanDongen)@dec.wa.gov.au
}

KEY WORDS: Wandoo, Landsat, Time Series, Vegetation, Wandoo Crown Decline

\begin{abstract}
:
In the forests of south west Western Australia dramatic declines in tree health have been observed in recent years. The species Eucalyptus wandoo has exhibited loss of crown foliage in increasing stages of severity; this condition is referred to as wandoo crown decline and can lead to death. Determining the extent and timing of these declines is difficult on the ground due to the large distribution of E. wandoo and the observation of tree declines at a range of locations and dates over the last 40 years. Understanding the distribution, severity and timing of these declines is essential to the identification of the causes of these impacts.

Investigation of time series Landsat imagery can inform on locations of crown foliage loss and the time periods these losses occurred in. Applying a vegetation index to a 20 year sequence of imagery enabled periods of decline to be identified. Employment of trend analysis of four date time series demonstrated the dynamics of wandoo crown cover. Comparisons of periods of decline with the variations of cover density over the entire image sequence facilitated the identification of possible locations and timing of wandoo crown decline impacts. Changes in crown cover observed by the imagery analysis were compared to field surveys.
\end{abstract}

\section{INTRODUCTION}

\subsection{Motivation}

Over the last forty years Eucalyptus wandoo (wandoo) crowns have demonstrated varying losses in canopy initially on terminal branches in some cases leading to death. This is described as wandoo crown decline (WCD). The Wandoo Recovery Group was formed in 2003 to research, map and communicate the incidence of wandoo crown decline (Manning 2009). The Wandoo Recovery Group and others (Whitford et al 2010, Brown et al 1986, Mercer 1991, 2003, 2008) have done various field assessments examining the severity and extent of WCD. The geographic extent and access prohibit comprehensive evaluation across the entire wandoo occurrence. Lack of knowledge about the timing and spread of phenomenon makes it difficult to understand and manage. These issues have instigated the following questions:

1) Where does wandoo crown decline (WCD) occur?

2) In what time period does WCD occur?

3) Is there recovery from the decline?

4) Is the recovery to previous canopy cover?

Time series satellite imagery can be utilised to inform these questions and improve understanding of WCD over the last 20 years across its mapped occurrence.

\subsection{Eucalyptus wandoo}

Eucalyptus wandoo is an iconic tree of the Western Australian wheatbelt and is valued for its wood and form. It is endemic to the south west corner of Western Australia extending 500 kilometres from Moora in the north to Mount Barker in the south along medium and low rainfall areas, generally 350- 1000mm (figure 1) (Caphill 1984). The tree can grow up to 30 metres high and achieve a girth of three metres, this reduces in lower rainfall zones (White and Manning, 2005).

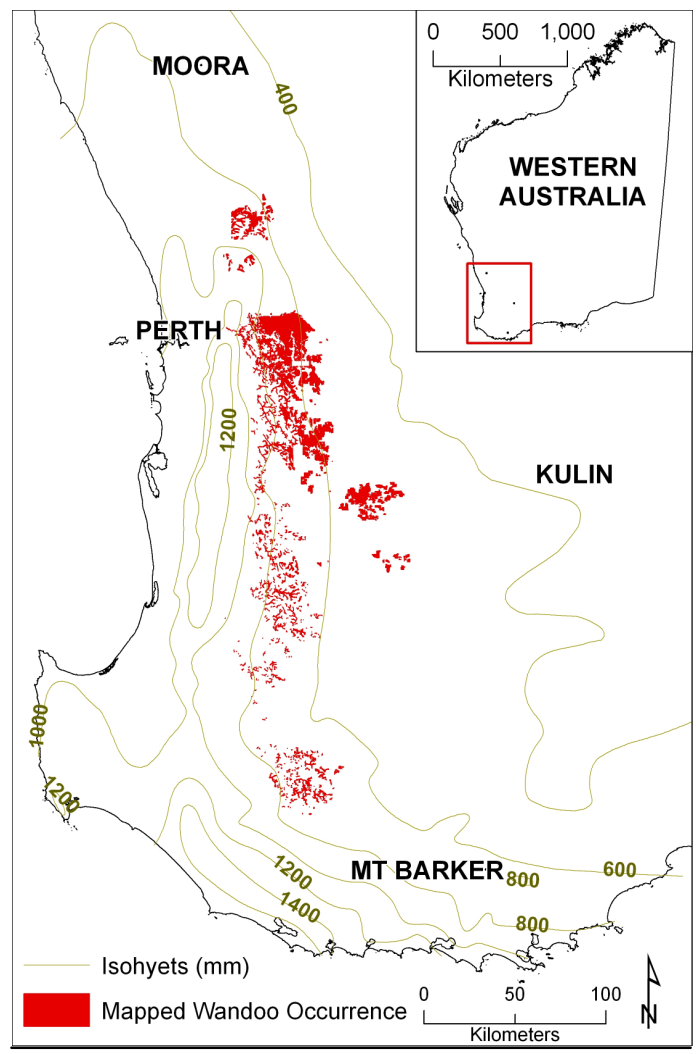

Figure 1. Locality of wandoo in south west Western Australia

\footnotetext{
* Corresponding author.
} 


\subsection{Trend Analysis}

Trend analysis has been employed in this investigation as it has proven useful in investigating vegetation cover dynamics in the south west of Western Australia and in other parts of Australia (Wallace and Thomas 1998, Curry et al 2008, Wallace et al 2006). The linear trend calculation requires a sequence of rectified and calibrated imagery from which spectral indices relating to variations in vegetation cover can be derived. Then changes between image dates can be summarised by calculating the linear regression (Furby et al, 2008).

Previous trend analysis in the south west of Western Australia on selected forest blocks containing mixed woodlands of wandoo, marri, jarrah and mallet trees has been conducted (Garkaklis and Behn, 2009). Long term trends in vegetation cover using image dates between 1988 and 2005 were created which were then validated in the field. Loss identified by the trend analysis was confirmed in the field, but not all of the loss was occurring in the wandoo trees but in co-occurring tree species. The long term trends used in the Garkalis and Behn study do not identify areas of recent recovery in canopy cover. This study aims to interrogate the time series of imagery and use shorter trend periods to inform the questions posed by the Wandoo Recovery Group.

\section{DATASETS}

\subsection{Landsat}

The satellite imagery utilised is Landsat 5 Thematic Mapper (TM) and Landsat 7 Enhanced Thematic Mapper Plus (ETM+) supplied by the Land Monitor Project (Caccetta et al 2000). In Western Australia the Land Monitor program used Landsat data initially to monitor salt affected land and remnant vegetation, and currently produces perennial woody vegetation monitoring products (Land Monitor, 2012). The images are captured in the dry season (summer) and are rectified and calibrated to base images. This processing makes the imagery suitable for time series and trend analysis. Image dates included in the analysis are 1990, 1992, 1994, 1996, 1998, 2000 and annually 2002 2010.

\subsection{Field Surveys}

The Wandoo Recovery Group has developed a technique for assessing wandoo crown decline (WCD). It categorises levels of active crown foliage loss along a scale ranging from healthy to dead (WRG 2005). The Wandoo Recovery Group has monitored the crown condition at 24 sites between 2006 and 2010 and determined trends in the crown condition over this time period. Surveys were of individual trees along transects on average $100 \mathrm{~m}$ long and $20 \mathrm{~m}$ wide. Jack Mercer established three long range transects with several sites along each and made observations of wandoo crown condition and stand health in 1991, 2002 and 2008 with the 2002 and 2008 field data being the most comparable (Mercer 1991, 2003, 2008).

In 2010 (10) and 2011 (8) sites were assessed for crown decline stage and canopy cover by the authors. These sites were chosen to be appropriate for use with Landsat imagery and were selected in areas of varying trends in vegetation cover. One hectare homogeneous sites were identified and three to five trees within a site assessed.

\subsection{Vector Data}

The study area has been restricted to the mapped occurrence of wandoo. The boundaries of wandoo occurrence were interpreted from airphotos and ground knowledge (figure 1). Wandoo does occur with other species (jarrah and marri) and can be mistaken for another species, powderbark wandoo $(E$. accedens). The mapped extent does not capture all wandoo woodlands and does include woodlands that are not wandoo. However restricting the analysis to this region enables broad observations of the wandoo woodlands to be made.

\section{PROCESSING}

\subsection{Index images}

Input to the trend analysis requires spectral index images that represent the land cover being investigated and vary linearly with changes. Index images were created using a combination of Band 3 and Band 5 of the Landsat imagery shown in equation (1).

$$
\text { (Band } 3+\text { Band 5) / } 2
$$

This band combination has been found in other studies in the south west of Western Austalia to be strongly related to changes in projected foliage cover (Zdunic and Behn 2009, Garkalis and Behn 2009). The index was calculated for all available images 1990 to 2010. The index for the 2000 image was later removed as this image has much ephemeral understorey growth not usually present in dry season imagery. In the winter of 1999 and into the summer months the rainfall was higher than average. Keeping the 2000 image in the analysis meant that it dominated the canopy cover in the image sequence and caused false gain and loss in the trend epoch calculations.

\subsection{Trend calculation}

The linear trends were calculated for several time periods (epoch) using orthogonal polynomials (Draper and Smith 1980) with software provided by CSIRO Mathematics, Informatics and Statistics. The output trend image contains the slope value scaled to fit 8-bit integer data range of 0-255. Firstly the trend for time periods 1990-2002 and 2002-2010 were calculated. These longer time periods enable examination of long term trends and are not as affected by individual image date conditions.

The long term linear trends were classified into five classes; decline, small decline, stable, small gain and gain cover classes. This enables areas to be calculated and the classes compared between the two time periods. Class boundaries were modified from previous products produced by the Land Monitor Project (Furby et al 2008).

A series of short epoch trend images were calculated using four image dates. In all eleven four date trend images were created by moving through the image sequence one date at a time. This sequence was produced as WCD can occur over several years not like other impacts like fire, flood or drought which have a strong impact and then recovery signal. The decline does not occur at the same time in all locations, but is diverse in its effect in time and space. By reducing the trend epoch length and calculating it for every available date the opportunity for 
identifying the effect of WCD across a large geographic area is increased.

\section{INVESTIGATION}

\subsection{General descriptive statistics}

These give an overview of the dynamics across the whole of the wandoo occurrence. From the sequence of index images the year of highest and lowest cover can be determined for a pixel and the areas summarised. The majority of areas with the highest cover were in the period 1990 to 1998 with 1990 covering $40 \%$ of the wandoo occurrence (figure 2). The largest areas of lowest cover occur in the period 2002 to 2010 with 2008 covering $28 \%$ of the area.

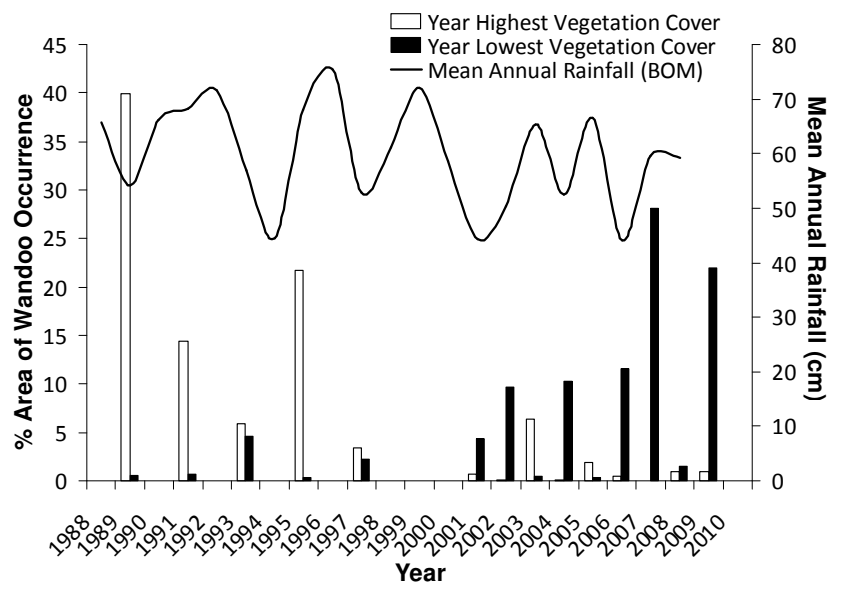

Figure 2. Bar graph showing percentage of wandoo occurrence area for each year in the image sequence with the highest and lowest cover. Line graph shows mean annual rainfall across wandoo occurrence from interpolated rainfall data (Bureau of Meterology Australia).

The longer trend epochs provide a general view of what is happening in the wandoo woodlands without being as affected by seasonality as the index image sequence and four date trends are. The long term trends show that the largest declines occurred during the period 1990-2002, this correlates with the observations of WCD in the late 1990's (Wills 2005, Manning 2009). Any decline in this period would be exacerbated by the 1990 high cover image. In the 2002-2010 period declines are still occurring, but not over the same extent, this change in decline area has been observed in Mercer (2008). In the 19902002 epoch the percentage area of the small decline class is $46 \%$ compared to $36 \%$ in the $2002-2010$ epoch. The stable area has increased from $31 \%$ to $40 \%$. Gain areas have increased in the more recent epoch with the small gain class changing from $2 \%$ to $4 \%$ and the gain class from $0.8 \%$ to $1.7 \%$. Recovery of previously impacted areas has been observed in recent years (Whitford et al 2010).

\subsection{Where does wandoo crown decline (WCD) occur?}

Red and blue displays of the long term linear trends enable geographic identification of areas of loss and gain in cover. These are constructed by assigning the slope component indicating decline to red and the gain component to blue. This approach was used with success in the Garkaklis and Behn (2009) study. Fire and other disturbances have not been removed from the trend calculation and need to be understood when examining the image. This type of display is very effective in communicating where there have been impacts on the vegetation cover.

The effect of fires on the trend imagery can be mitigated by using the four date trends in the same display process. The image date with a fire impact will influence these trend images, but will not have the enduring impact on the sequence it does in the long term trends.

\subsection{In what time period does WCD occur?}

In the four date trend epochs decline is apparent in all images. Comparison of the magnitude of declining trends above stable (i.e. slope) for all four date epochs yields interesting results. On a per pixel basis the maximum declining and gaining values above stable were determined and the epoch identified. Area calculations show that the greatest area of declines are observed in the 1996-2003 epoch (figure 3), with 46\% of the wandoo occurrence. Other large areas of decline occur in the epochs 1994-2002 (10\%) and 2004-2007 (12\%). This method assists to increase the certainty of determining when declines occurred and is more specific than the longer term trends.

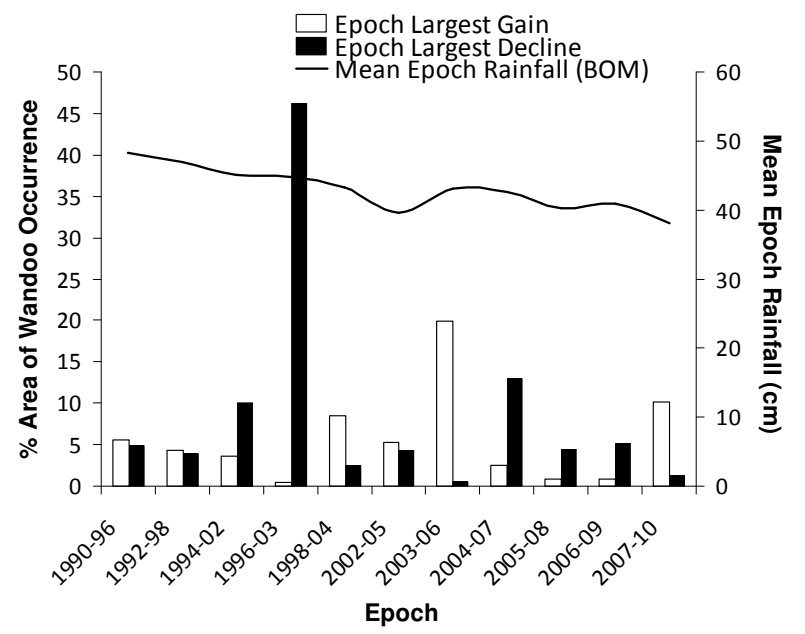

Figure 3. Bar graph showing percentage of wandoo occurrence area for each four date epoch with the largest declining and gaining trend in cover. Line graph shows mean epoch rainfall across wandoo occurrence from interpolated rainfall data (Bureau of Meterology Australia).

\subsection{Is there recovery from the decline?}

From previous studies of WCD and the four date trends the greatest observations of crown decline were in the period 1998 to 2003. Therefore the trend classification of the period 20022010 should show some of the recovery. In this epoch the gain and stable class areas have increased and the decline class areas decreased compared to the previous 1990-1998 epoch

When querying the sequence of four date epoch trends the areas with a gaining trend above stable only covered $62 \%$ of the wandoo occurrence, whereas the decline trend area covered $96 \%$. Of the areas with a gaining trend the largest trends are observed in the epochs 2003-2006 (20\%) and 2007-2010 $(10 \%)$. In five years of surveys from 2006 to 2010 , by the 
Wandoo Recovery Group, overall a sight improvement has been observed in the wandoo crowns (Whitford et al 2010).

Whether any increase in cover identified in the imagery is due to wandoo crowns improving needs to be validated in the field. These locations can be identified in the trend imagery displays.

\subsection{Is the recovery to previous canopy cover?}

The spectral image index utilised represents increasing cover with lower index values. Therefore by subtracting the highest cover value in image sequence from the 2010 index cover value, an image may be produced showing the difference between the current cover and the highest cover. Pixel values of zero indicate that 2010 is the year of highest cover, and positive values the difference. A frequency histogram of the differences may be produced. The histogram shows that the majority of values are in the range 0 to 30 with an average of 12.58 . Using information from field sites observed by the authors an index value of 12.58 can be related to a projective foliage cover of approximately $7 \%$. 2010 is the year of highest cover for $1.5 \%$ of the total area.

The cover in wandoo woodland is generally less than $40 \%$ (Hewett and Underwood 1963). Therefore a difference on average of $7 \%$ in projected foliage cover between the 2010 cover and the highest year of cover is considerable. The canopy shape of trees recovering from WCD is of a different form to the healthy tree. Originally the tree would have a wide canopy with leaves at the ends of branches and in recovery this changes to clumps of leaves forming along the main branches, these are called epicorms. Due to this contraction of the crown during WCD and initial recovery, there will probably be a delay in canopy recovery being observable in a $25 \mathrm{~m}$ Landsat pixel.

\subsection{Issues}

Fire impacts will influence the trends and may mask declines and recovery attributable to other causes. Due to the scale at which fire history data has been collected it is not feasible to mask these areas, but where declining trends are identified, any fires occurring in the epoch could be attributed to refine the analysis.

Climate and seasonality will affect the cover observed in summer. The drying trend of the last ten years may be causing a loss of cover, and whether is or isn't related to WCD is unknown. Mercer (2008) did find a trend of decreasing crown rating with decreasing rainfall as field sites moved west to east, but no relationship with average annual rainfall.

The image sequence has not been terrain corrected. Although the terrain is not rugged, other work in the south west Western Australian forests has shown that where there is a difference in time of year of a few months subtleties in the cover index images are affected. Repeating the analysis with terrain corrected imagery would give greater certainty that the differences observed were real on ground changes.

Cloud masking will affect the trend calculation especially the four date trends, the areas affected are minimal and no areas have less than three dates from which to calculate a trend.

\section{CONCLUSION}

Further investigation could look at other ancillary data such as position in landscape. This attribute was found to have a significant correlation with WCD in Mercer 2008. Statistical analysis of significance of differences between years and epochs would direct the interrogation of the results to the most important changes.

This method of interrogating an appropriately processed time series of Landsat imagery has proven useful in extending the understanding crown declines in the native forests in Western Australia. The time periods of canopy loss identified by the analysis correlate well with previous surveys and observations. Of the field sites visited in 2011 that were wandoo woodland all showed signs of previous crown decline and varying levels of recovery or lack of. Future field sites to confirm decline impact and recovery can be identified from the trend imagery.

\section{REFERENCES}

Brown, P., and Tippett, J. 1986. The role of biotic agents in the rural decline of Eucalyptus wandoo Blakely in South-West Western Australia. Report prepared by CALM Science Division, Como, Western Australia.

Caccetta, P. A., Campbell, N. A., Evans, F. H., Furby, S. L., Kiiveri, H. T. and Wallace, J. F. 2000. Mapping and monitoring land use and condition change in the South-West of Western Australia using remote sensing and other data, Proceedings of the Europa 2000 Conference, Barcelona.

Capill, L. G. I984. Wandoo Woodland Conservation. A proposal for a system of ecological reserves. Campaign to Save Native Forests (W.A.).

Curry, P., Zdunic, K., Wallace, J. and Law, J. 2008. Landsat monitoring of woodland regeneration in degraded mulga rangelands: implications of arid landscaped managed for carbon sequestration, In: Proceedings $14^{\text {th }}$ Australian Remote Sensing and Photogrammetry Conference, Darwin, Australia.

Draper, N. and Smith, H., 1980. Applied Regression Analysis, Second Edition, Wiley: New York, pg. 266.

Furby, S., Zhu, M., Wu, X. and Wallace J.F. 2008. Vegetation Trends 1990-2008 South West Agricultural Region of Western Australia, Land Monitor II Project, CSIRO MIS, Available at: http://www.landmonitor.wa.gov.au/reports/landmon_II/LM2008 _VegTrend_1990_2008.pdf

Garkaklis M. and Behn, G. 2009. Assessment of Eucalyptus Wandoo (Wandoo) and other tree canopy decline using Landsat Trend Analysis, Report to Department of Environment and Convservation, Western Australia, pg 15.

Hewett, P.N. and Underwood, R.J. 1963. The wandoo forest. Department of Conservation and Land Management, Woodvale, Western Australia.

Land Monitor, 2012. Land Monitor A project of the Western Australian Salinity Action Plan supported by Natural Heritage Trust, http://www.landmonitor.wa.gov.au, [21 Mar 2012]. 
Manning, L. 2009. Five years caring for wandoo, In: Western Wildlife, Perth, Western Australia, Vol. 13, No. 1, pp. 6-7.

Mercer, J.W. 1991. Decline of Eucalyptus wandoo Blakely in the Western Australian wheatbelt area. B.Sc. (Hons.) thesis, Biological and Environmental Sciences, Murdoch University, Perth, Western Australia.

Mercer, J.W. 2003. Survey of Eucalyptus wandoo decline. Report prepared for CALM Science Divison, Como, Western Australia.

Mercer, J.W. 2008. Second Survey of Eucalyptus wandoo decline: Final report, June 2008. A report on wandoo decline on behalf of the Wandoo Recovery Group, Department of Environment and Conservation and WWF-Australia.

Wallace J.F and Thomas P. 1998. Rangeland Monitoring in Northern Western Australia using Sequences of Landsat Imagery. Report to the WA Pastoral Lands Board. CSIRO MIS, Agriculture WA. Available at:

http://www.cmis.csiro.au/rsm/research/pdf/plb_summaryrep.doc

Wallace, J.F., Behn, G. and Furby, S.L. 2006. Vegetation condition assessment and monitoring from sequences of satellite imagery. Ecological Management and Restoration, Vol7,

S1 pp31-36.

WRG (Wandoo Recovery Group) 2005. Surveying wandoo crown decline - A guide for assessors. Wandoo Recovery Group and Department of Conservation and Land Management, Kensington, Western Australia.

Wills, A. 2005 Crown decline in wandoo: observations form Wundabiniring Brook 1999-2005, Department of Environment and Conservation, Kensington, Western Australia.

White, P. and Manning, L. 2005 Wondering about wandoo, In: Landscope, Perth, Western Australia, Vol. 20, No. 3, pp. 17-21.

Whitford, K., Manning, L., Wills, A. 2010. Wandoo Crown Condition 2010: Report of five years of wandoo crown decline surveys. Wandoo Recovery Group, Department of Environment and Conservation, Western Australia.

Zdunic K., Behn G. 2009. Exploiting time sequences of satellite imagery to monitor landscape aspects, Proceedings Spatial Sciences Conference, Adelaide, South Australia.

\section{ACKNOWLEDGEMENTS}

The Wandoo Research Group and Department of Environment and Conversation funded this research. In particular the impetus of Liz Manning and Paul Brown, information and field assistance from Peter White and historical insights from Allan Wills. 